\title{
Análise de processos de produção textual-discursiva e práticas multiletradas em minicurso virtual
}

\author{
Analysis of textual-discursive composition processes and multiliterate practices in virtual mini \\ course \\ Análisis de procesos de producción textual-discursivos y prácticas multiletradas en minicurso \\ virtual
}

Recebido: 13/01/2022 | Revisado: 17/01/2022 | Aceito: 26/01/2022 | Publicado: 27/01/2022

Ricardo Jorge de Sousa Cavalcanti

ORCID: https://orcid.org/0000-0001-6990-6669 Instituto Federal de Educação, Ciência e Tecnologia de Alagoas, Brasil

E-mail: ricardo.cavalcanti@ifal.edu.br

Rossana Viana Gaia

ORCID: https://orcid.org/0000-0001-7592-1881 Instituto Federal de Educação, Ciência e Tecnologia de Alagoas, Brasil E-mail: rossana.gaia@ifal.edu.br

Daniel Amorim de Oliveira Felix

ORCID: https://orcid.org/0000-0002-2730-9660 Instituto Federal de Educação, Ciência e Tecnologia de Alagoas, Brasil E-mail: daof1@aluno.ifal.edu.br

Erick Robert Ferreira da Silva

ORCID: https://orcid.org/0000-0003-1898-3837 Instituto Federal de Educação, Ciência e Tecnologia de Alagoas, Brasil E-mail: erfs2@aluno.ifal.edu.br

Gustavo Correia dos Santos

ORCID: https://orcid.org/0000-0002-9250-0752 Instituto Federal de Educação, Ciência e Tecnologia de Alagoas, Brasil

E-mail: gustavo.correia@ifal.edu.br

\begin{abstract}
Resumo
Este artigo analisa processos de produção textual-discursiva em práticas multiletradas na formação inicial docente e ações investigativas (formativas) netnográficas, na perspectiva de desenvolvimento dos letramentos acadêmicodocente e digital de práticas multiletradas em processos de escrita por sujeitos do Curso de Licenciatura em LetrasPortuguês, da modalidade presencial. O corpus de análise é composto por comentários e produção textual (artigo de opinião) dos estudantes no $1^{\circ}$ módulo do minicurso do projeto Da escrita convencional à tela: inter-ações multiletradas no processo formativo docente (PIBIC). A metodologia incluiu quatro etapas. A primeira etapa permeou (i) a leitura e discussão de referencial teórico; seguidamente, (ii) a elaboração de convite; por extensão, (iii) a divulgação do minicurso; por fim, (iv) a definição de etapas do módulo, elaboradas no total de 4 semanas. Como método de investigação, numa perspectiva qualitativa de pesquisa em educação, elegemos a pesquisa-ação, de cunho colaborativo. O estudo confirmou a necessidade de promoção de eventos on-line de fomento das práticas docentes que carecem constantemente de ressignificações. Vimos desenvolvendo ações que têm nos levado ao atendimento categorias relativas às práticas textual-discursivas em ambientes virtuais multiletrados, cuja abordagem se filia a estudos netnográficos.
\end{abstract}

Palavras-chave: Multiletramentos; Produção textual; Letramentos; Letramento digital; Ensino.

\begin{abstract}
This paper analyzes composition procedures in the areas of text and discourse in multiliteracy practices in the early teacher education and investigatives netnographic actions (professional) in the view of academic and teaching literacies development as well as digital multiliterate practices in processes of writing, by people from the Language Portuguese Course, from the in the presential modality. The corpus of analysis is compound by commentaries and textual composition (opinion articles) from students of the first module of the project "From the usual writing to the screen: multiliterate inter-actions in the teacher formative process" (PIBIC research). The methodology included four steps. The first was (i) reading and discussion of the theoretical framework, (ii) drafting an invitation, then (iii) minicourse divulgation, at last, (iv) definition about module's steps, elaborated in a total of 4 weeks. As a method of investigation, in a qualitative perspective of research in education, we chose the action research, with a collaborative scope. As a research method, in a qualitative perspective of research in education, there has been chosen the researchaction. The study has confirmed the need of promoting online events which foster teaching practices that constantly
\end{abstract}


need ressignifications. We have been developing actions that have led us to the contemplation of some categories that are text and discourse related in multiliterate virtual environments, affiliated to netnographic studies.

Keywords: Multiliteracies; Text composition; Literacies; Digital literacy; Teaching.

\section{Resumen}

Este artículo analiza procesos de producción textual-discursiva en prácticas multialfabetizadas en la formación inicial docente y acciones investigativas (formativas) netnográficas, bajo la perspectiva de desarrollo de las alfabetizaciones académico-docente y digital y de las prácticas de multialfabetización en procesos de escritura por sujetos del Curso de Licenciatura en Letras-Portugués, en la modalidad presencial. El corpus de análisis está compuesto por comentarios y producción textual (artículo de opinión) de los estudiantes en el primer módulo del minicurso del proyecto De la escritura convencional a la pantalla: interrelaciones multialfabetización en el proceso formativo docente (PIBIC). La metodología incluyó cuatro pasos. La primera fue (i) lectura y discusión del marco teórico, (ii) redacción de una invitación, luego (iii) divulgación con (iv) definición posterior de los pasos del módulo, elaborados en un total de 4 semanas. Como método de investigación, en una perspectiva cualitativa de la investigación en educación, hemos elegido la investigación acción, de carácter colaborativo. Como método de investigación, en una perspectiva cualitativa de investigación en educación, elegimos la investigación-acción, de carácter colaborativo. El estudio confirmó la necesidad de la promoción de eventos en línea para fomentar las prácticas docentes que necesitan permanentemente de replanteamientos. Hemos estado desarrollando acciones que nos han llevado a la observación de algunas categorías relativas a las prácticas textual-discursivas en ambientes virtuales de multialfabetismo, cuyo enfoque se afilia a estudios netnográficos.

Palabras clave: Multialfabetización; Producción textual; Alfabetismos; Alfabetismo digital; Enseñanza.

\section{Introdução}

Para fins de introdução, demarcamo-nos semelhantemente a estudiosos/as que tratam da relevância que os processos de alfabetização se deem em consonância com os de alfabetização, isto é, tão difundida máxima de "alfabetizar letrando" e/ou "letrar alfabetizando". Com isso, evidentemente, ser capaz de juntar letras e de escrever um texto é algo diferente, por exemplo, de conseguir se expressar de forma tal que os outros compreendam o ponto de vista de vista apresentado/defendido. Nesse sentido, "ser letrado" enseja consegue compreender aquilo que se lê e, ainda, estabelecer inferências necessárias com as condições às quais o texto-discurso foi produzido/acionado.

Com efeito, pode-se inferir que o letramento tem a ver com a prática social, dependente dos contextos nos quais a língua escrita se inscreve. Portanto, não há "o letramento", mas vários letramentos, já que existem diversificados significados atribuídos à escrita e à leitura, a depender do meio no qual os sujeitos estão inseridos, considerando, sobretudo, cultura ágrafa $\mathrm{x}$ grafocêntrica, além de práticas linguageiras predominantemente orais ou escritas.

Na perspectiva de várias formas de letramento, deve-se levar em conta também a oralidade. Não se pode considerar superior uma sociedade que usa a escrita, em relação a uma que se comunica mormente de forma oral. A comunicação oral pode ser tão importante quanto a escrita. É nesse sentido que hoje não mais se trabalha "o letramento", mas os multiletramentos. A respeito dessa discussão, há trabalhos publicados de Marcuschi, como a obra: "Da fala para a escrita: atividades de retextualização" (2001).

A teoria relativa à pedagogia dos multiletramentos, cuja origem remonta ao Grupo Nova Londres, em meados dos anos 1990, tem sido fortalecida no Brasil a partir de eventos e publicações direcionados exclusivamente a este debate. A despeito da distância temporal do lançamento do manifesto que lançou este debate, verifica-se que há culturas e produções multimodais, na contemporaneidade, ainda ignoradas no ambiente da sala de aula, mesmo que presentes no cotidiano de estudantes e professores/as. Para Rojo (2012, p. 13), o termo multi nas expressões multiculturalidade - que classifica sociedades globalizadas - e multimodalidade - que identifica as formas de comunicação e de informação dos grupos nestes contextos - é o que possibilita ao grupo Nova Londres inaugurar o termo multiletramentos.

Essa ideia deve estar presente desde a formação dos/as professores/as, ou seja, é necessário contemplar letramento, letramento literário, leitura, compreensão leitora e literatura. Faz-se imperativo também destacar que os/as docentes precisam ter condições de transformar aquilo apreendido em seu curso universitário em atividades práticas significativas para seus 
alunos. Isso reforça a importância de cursos como o que nos dispomos a ofertar/ analisar, em que são abordadas tecnologias relevantes ao contexto atual de formação/letramento inicial docente.

Nesse sentido, a ideia de letramento visa a inserir na sala de aula, por meio dos currículos escolares, a diversidade cultural de uma sociedade amplamente mundializada. O principal objetivo desses estudos é ampliar o debate acerca de ideias plurais que possam fomentar a tolerância a partir do respeito à alteridade. Essa diversidade está prevista, inclusive na Base Nacional Comum Curricular (BNCC), que visa a reconhecer o/a estudante como um sujeito sócio-histórico. O documento apresenta como um dos objetivos: compreender as linguagens como construção humana, histórica, social e cultural, de natureza dinâmica, reconhecendo-as e valorizando-as como formas de significação da realidade e expressão de subjetividades e identidades sociais e culturais (Brasil, 2018). Essa compreensão é um dos objetivos da BNCC, explícito no seguinte excerto:

1. Valorizar e utilizar os conhecimentos historicamente construídos sobre o mundo físico, social, cultural e digital para entender e explicar a realidade, continuar aprendendo e colaborar para a construção de uma sociedade justa, democrática e inclusiva. (grifos nossos) (p.07)

O fortalecimento do termo no Brasil é identificado na recente publicação do documento intitulado Base Nacional Comum Curricular (BNCC). O Documento (Brasil, 2018) tem caráter normativo e definidor das aprendizagens essenciais da educação básica em todo Brasil e o termo multiletramento(s) é registrado 11 vezes, o que evidencia a importância dessa teoria na formatação de currículos regionais em todo o território brasileiro. Verifica-se que a pedagogia dos multiletramentos apresenta-se como desafio na BNCC, pois cabe às escolas, em seus distintos níveis, reorganizar o currículo com esse encaminhamento.

A BNCC propõe, nessa perspectiva, rever as linguagens que circulam e entender os seus mecanismos nos processos de comunicação, o que inclui identificar aspectos de "manipulação" (Brasil, 2018, p. 61). Com essa revisão, o documento propõe que a educação efetive "usos mais democráticos das tecnologias e para uma participação mais consciente na cultura digital" (Brasil, 2018, p. 61), o que sugere novas propostas aos processos de ensino-aprendizagem que incluam interatividade e compartilhamento entre pares, ou seja, relações de troca de saberes entre professores/as-estudantes e estudantes-estudantes.

Citando mais uma vez de forma explícita trechos da BNCC, percebemos a ênfase nas variadas formas de letramento, contemplando, inclusive, a digitalidade:

4. Utilizar diferentes linguagens - verbal (oral ou visual-motora, como Libras, e escrita), corporal, visual, sonora e digital -, bem como conhecimentos das linguagens artística, matemática e científica, para se expressar e partilhar informações, experiências, ideias e sentimentos em diferentes contextos e produzir sentidos que levem ao entendimento mútuo.

5. Compreender, utilizar e criar tecnologias digitais de informação e comunicação de forma crítica, significativa, reflexiva e ética nas diversas práticas sociais (incluindo as escolares) para se comunicar, acessar e disseminar informações, produzir conhecimentos, resolver problemas e exercer protagonismo e autoria na vida pessoal e coletiva. (grifos nossos) (p.07)

Sobre o uso democráticos das tecnologias, cabe apontar nesta discussão como essa necessidade se mostrou acentuada durante e por conta da pandemia por corona vírus (2020/2021), que tem colocado em xeque concepções de ensino, escola, sala de aula, aula, práticas docentes; a educação, de modo geral, a partir de novas (re)configurações.

Outro conceito pertinente a este debate é o de netnografia, noção que se desenvolve pela necessidade de um termo para atualizar o conceito de etnografia em ambiente virtual de aprendizagem. Uma das contribuições vindas dos estudos do letramento à nossa tradição de pesquisas é trazer a perspectiva etnográfica como uma possibilidade de construir uma articulação entre o texto e o contexto na abordagem da escrita (Fiad, 2015).

As mudanças sociais cobram atualizações e revisões de conceitos. Desse modo, a etnografia, conforme Van Mannen 
(2006, p. 15), sai do âmbito de estudos isolados em um único local e passa a abordar aspectos relevantes em processos migratórios, povos originários e suas relações com processos globalizantes, tecnologias e usos de transportes a partir de aplicativos, além de outras ideias. A mudança de eixo teórico gerou o que se denomina "embaralhamento e interpenetração dos modos de pensamento e ação em todo o mundo". O debate sobre multiletramento, portanto, inclui também aspectos da cibercultura com observações acerca do mapeamento feito por empresas capitalistas para identificar circulação de pessoas a partir de chips de celulares, o que possibilita tanto ao governo quanto a empresas identificar, rapidamente, cenários e tendências, de comportamento e de consumo.

As constantes mudanças tecnológicas e seu impacto social implicaram atualização metodológica da etnografia para as comunidades virtuais desterritorializadas. Nesse debate, insere-se a Pesquisa "Da escrita convencional à tela: inter-ações multiletradas no processo formativo docente", PRPPI/PIBIC/Ifal (2020/2021 - CNPq), cujo objetivo foi desenvolver ações investigativas em processos formativos docentes, na perspectiva netnográfica e com base no desenvolvimento dos letramentos acadêmico-docente e digital na formação inicial de professores. O estudo investigou processos de produção textual-discursiva em práticas multiletradas na formação inicial docente. Para isso, conta com análises pautadas em categorias também vinculadas ao letramento acadêmico-docente, a partir do perfil dos/as licenciandos/as matriculados/as no Curso de Licenciatura em Letras-Português, em um dos campi de uma instituição federal pública da área metropolitana na cidade de Maceió-AL. A pesquisa também propôs apresentar à comunidade acadêmico-científica, ao final de sua execução, um produto educacional, em formato de e-book, sobre práticas acadêmicas multiletradas.

O estudo definiu cronograma de atividades síncronas e assíncronas. Para o módulo inicial do minicurso, intitulado "Abordagens ativas e multiletramentos no ensino de LP", foram identificados aspectos dos letramentos acadêmico-docente e digital na formação docente de licenciandos em Letras-Português da modalidade presencial, os quais discutiremos mais adiante ao longo deste artigo. As ações investigativas e formativas no ambiente virtual (doravante AVA), e que integram a metodologia, incluíram, inicialmente, a seleção de material para as postagens na sala de aula virtual. Os processos interativos, a partir dos comentários sobre as atividades, foram observados, sendo os pesquisadores também inseridos no processo. A análise ocorreu ao longo de todo o módulo do minicurso, via interações no AVA (Google Classroom) e no Google Meet durante o momento síncrono. Outro aspecto da análise ocorreu nas produções textuais materializadas em comentários e por meio de áudios no aplicativo WhatsApp, além de estar presente no gênero artigo de opinião, produto final depositado pelos cursistas ao término do primeiro módulo do minicurso. Com efeito, o espaço virtual pode ser entendido, também, como uma ação (auto)formativa.

Tendo em conta os objetivos específicos de problematizar aspectos ligados aos processos de produção textualdiscursiva em práticas multiletradas na formação inicial docente e o de discutir categorias ligadas ao letramento acadêmicodocente a partir do perfil dos licenciandos inseridos no Curso, discutiu-se, em encontros síncronos iniciados em agosto de 2020 e concluídos em dezembro desse mesmo ano, um aporte teórico para debater questões ligadas à produção textual-discursiva, aos multiletramentos e à formação docente, a exemplo de Rojo (2012), Ribeiro (2020), Noveli (2010), Pereira e Monteiro (2019), Ferraz (2019), Branco et al (2019), Castro (2020), Ramos (s/d), Cavalcanti e Felix (2020), Cardoso, Cavalcanti e LimaDuarte (2020), Silva e Pereira (2015); além de lives com Coscarelli (2020), Antunes (2020), Rojo (2020), Cavalcanti (2020) entre outros.

\section{Metodologia}

A metodologia desta investigação-ação se insere numa perspectiva qualitativa de pesquisas educacionais, tendo em vista os procedimentos relativos à divulgação dos objetivos da pesquisa entre os/as licenciandos/as - que estão na formação inicial da carreira docente. $\mathrm{O}$ estudo trabalhou com a adesão colaborativo-voluntária por parte desses sujeitos, matriculados em 
distintos períodos do Curso de Licenciatura em Letras-Português, no âmbito de um campus pertencente à Rede Federal de Ensino do município de Maceió/AL (Lüdke e André, 1986; Thiollent, 1988).

Como método de investigação, foi utilizada a pesquisa-ação, de cunho colaborativo (Ibiapina, 2008), por possibilitar, conforme os objetivos do presente estudo, maior interação entre os sujeitos envolvidos - pesquisadores e colaboradores em contextos de formação docente - e o objeto implicado: produção de gêneros acadêmicos com práticas multiletradas em espaços virtuais de aprendizagem.

O estudo também integra a abordagem netnográfica, que subsidia discussões sobre pesquisas em espaços virtuais para definir procedimentos relacionados à constituição dos corpora e os critérios de escolha textual-discursiva para realizar análises (Noveli, 2010). Tal discussão, neste trabalho, está relacionada aos aspectos conceituais de multiletramentos, letramento digital, multimodalidade e hipertextualidade (Coscarelli e Ribeiro, 2017; Rojo e Moura, 2012; Ribeiro, 2016; Shepherd e Saliés; 2013), por serem práticas de produção escrita em contextos acadêmicos de formação de professores.

Para tanto, a pesquisa ampliou as investigações com estudos acerca de gêneros acadêmico-científicos, com ênfase na hipertextualidade, na BNCC (Brasil, 2018), e no ensino de Língua Portuguesa. As observações incluíram multissemioses e multimodalidades. Outro aspecto de relevo no estudo foram as concepções sobre práticas multiletradas no ensino de Língua Portuguesa.

Ao longo da primeira etapa da pesquisa, após e durante encontros síncronos, ocorridos entre agosto e setembro de 2020, via Google Meet, e momentos assíncronos entre orientador, coorientadora, bolsista e voluntário, ficou definido que o minicurso teria formato de cinco módulos, cada um com 20 horas, totalizando carga horária total de 100 horas. A primeira oferta se deu no período de 17 a 27 de novembro de 2020. Com base nos estudos iniciais, foi elaborado e realizado o primeiro módulo, intitulado "Noções sobre multiletramentos na BNCC". A divulgação do primeiro módulo do minicurso foi realizada virtualmente, entre os/as licenciandos/as matriculados/as em diversos períodos do Curso analisado.

Foi definido e planejado o AVA Google Classroom por ser uma plataforma acessível e utilizada no âmbito da instituição selecionada, no período de pandemia, quando foi adotado o formato de Ensino Remoto Emergencial (ERE). Os pesquisadores tiveram acesso também ao diagnóstico sobre o auxílio conectividade ${ }^{1}$, organizado pela instituição para dar suporte aos/às estudantes que precisassem e solicitassem no período do edital, as seguintes opções: auxílio financeiro de 70 reais mensais ou compra de equipamento para acesso à internet, o que podia ser tablet, celular e/ou chip.

\subsection{Procedimentos metodológicos: desdobramentos da oferta do primeiro módulo do Minicurso}

O Minicurso foi composto por atividades remotas nos formatos assíncronos e síncronos. Dentre as atividades assíncronas, foram elaborados podcasts de apresentação e de abertura do Minicurso, produzidos pela equipe de estudoinvestigação. Os/as licenciandos/as tiveram acesso, inicialmente, ao Termo de Consentimento Livre e Esclarecido (TCLE), a um questionário-perfil (via Google Formulários) e ao cronograma das atividades, no formato PDF. Além desses materiais, foram postados na plataforma vídeos e textos referenciais gratuitos e/ou liberados em formato Creative Commons sobre a temática proposta, como a live Multiletramentos e TDIC em tempos de pandemia, com a Profa. Roxane Rojo, organizada pelo Grupo Gellite (CNPq/Ufal); o podcast Diálogos com a educação - Multiletramentos e as tecnologias Digitais, organizado pelo grupo de pesquisa Multiletramentos e usos das Tecnologias Digitais da Informação e Comunicação na Educação (MULTDIC), via Canal no YouTube; além do Documento BNCC (disponibilizado na íntegra para consultas) e 6 vídeos institucionais de curta metragem, discutindo o documento ( $O$ que é a Base Nacional Comum Curricular (BNCC)?

\footnotetext{
${ }^{1-}$ Para mais detalhes, acesse: https://www2.ifal.edu.br/campus/maceio/noticias/ifal-maceio-abre-segunda-etapa-para-adesao-ao-auxilioconectividade.
} 
Fundamentos pedagógicos; O papel da Língua Portuguesa; Importância BNCC; Características, princípios e fundamentos pedagógicos do Ensino Fundamental Anos Finais; e Novos e multiletramentos).

No estudo, foi utilizado também o aplicativo WhatsApp em dois momentos semissíncronos para interações a partir do Google Classroom. Após terem lido os textos, assistido aos vídeos e ouvido os podcasts, os/as participantes foram convidados/as a clicar nos links que os/as direcionava a um grupo no aplicativo; no local para descrição do grupo, fixamos as seguintes perguntas motivadoras para possíveis interações (foram dois grupos para dois momentos distintos): Após terem ouvido esse breve e introdutório podcast sobre os multiletramentos, qual a importância de estarmos discutindo este conceito em plena pandemia e tendo como recorte o tratamento que the é dado pela BNCC (que veremos ao longo do curso), especificamente quanto ao ensino de Língua Portuguesa?; e vocês repararam que a Professora Roxane Rojo (2020), num dado momento da sua fala, sugere substituir os livros de papel por livros digitais? Levando em consideração as colocações da educadora, tanto na live quanto no texto disposto no AVA, e fazendo um contraponto com a experiência de escolas e salas de aulas que vocês têm, o que acham dessa possibilidade?. Verificaram-se, em todos os momentos descritos, formas distintas de interação dos/as participantes e dos/as organizadores do Minicurso, em maior ou menor intensidade. A tônica desse módulo foi orientar os/as participantes a desenvolverem autonomia nos estudos da pesquisa, dando oportunamente as devolutivas requeridas a partir das interações que aconteceram naquele AVA.

Reitera-se, com isso, que a pesquisa-ação colaborativa, com o aporte da Netnografia, pode, inclusive, promover preceitos teórico-práticos no percurso formativo inicial docente. No caso do minicurso, o objetivo foi contribuir com reflexões teórico-práticas de ensino de Língua Portuguesa com o aporte da Pedagogia dos Multiletramentos (Rojo e Moura, 2012). Os encontros e as oficinas foram certificados pelo Grupo de Estudos e Pesquisas em Educação Profissional e Tecnológica (GEPEPT/CNPq/Ifal), vinculado ao ProfEPT/Ifal, do qual os/as pesquisadores/.as orientadores/as deste trabalho são membros integrantes.

Os resultados posteriores do trabalho serão difundidos em eventos diversificados, além da publicação de trabalhos em formato de artigo acadêmico em periódicos, sendo este presente artigo parte das metas de compartilhamento metodológico do estudo entre pares. A etapa final do e-book, conforme destacado anteriormente, está em fase final e também será difundido com a comunidade acadêmico-científica, como um dos resultados da pesquisa. A seguir, no tópico destinado à discussão a respeito do Minicurso on-line, dispomos, inicialmente, a representação do panfleto utilizado para divulgação, conforme é apresentada na Figura 1.

\subsection{Minicurso on-line: da idealização à realização}

Figura 1 - Panfleto digital para divulgação.

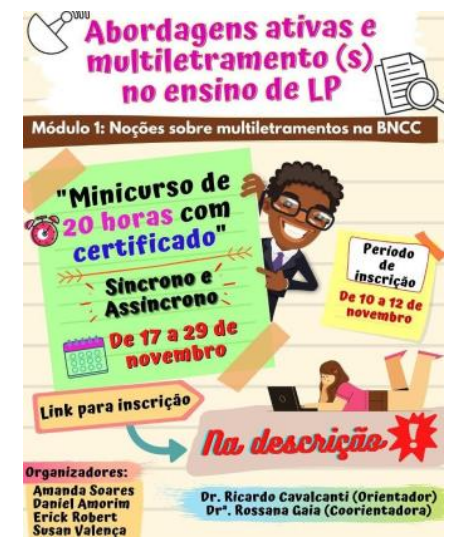

Fonte: Autores (2020). 
Para a etapa de divulgação do minicurso, elaboramos um panfleto digital, compartilhado em aplicativos de mensagens e redes sociais. Buscamos criar um material que fosse informal, mas que, ao mesmo tempo, contivesse as informações necessárias para estimular a participação.

Para se chegar ao fechamento do banner de divulgação presente na Figura 1 contou-se com algumas prerrogativas, que julgamos essenciais a esse exemplar de texto, tendo em vista a sua constituição como gênero e a sua projeção em diferentes esferas da virtualidade, especialmente, nos momentos que ensejam o distanciamento físico. As cores, as fontes das letras e as imagens visam a tornar o curso uma escolha atrativa. O menino apontando a carga horária e a menina deitada, utilizando o laptop, chamam a atenção para a possibilidade de os/as estudantes poderem participar do minicurso em suas casas, além de garantirem 20 horas certificadas.

A seguir, por meio de print do AVA (Figura 2), destacamos a imagem da página inicial do Ambiente Virtual utilizado (Google Sala de Aula) do Minicurso, com logotipo criado pelos organizadores, título e datas. Note-se que, desde a primeira página, propiciou-se a interação dos/as participantes entre si e com os/as organizadores/as, por meio de publicações que permitiam comentários.

Figura 2 - Página inicial do AVA.

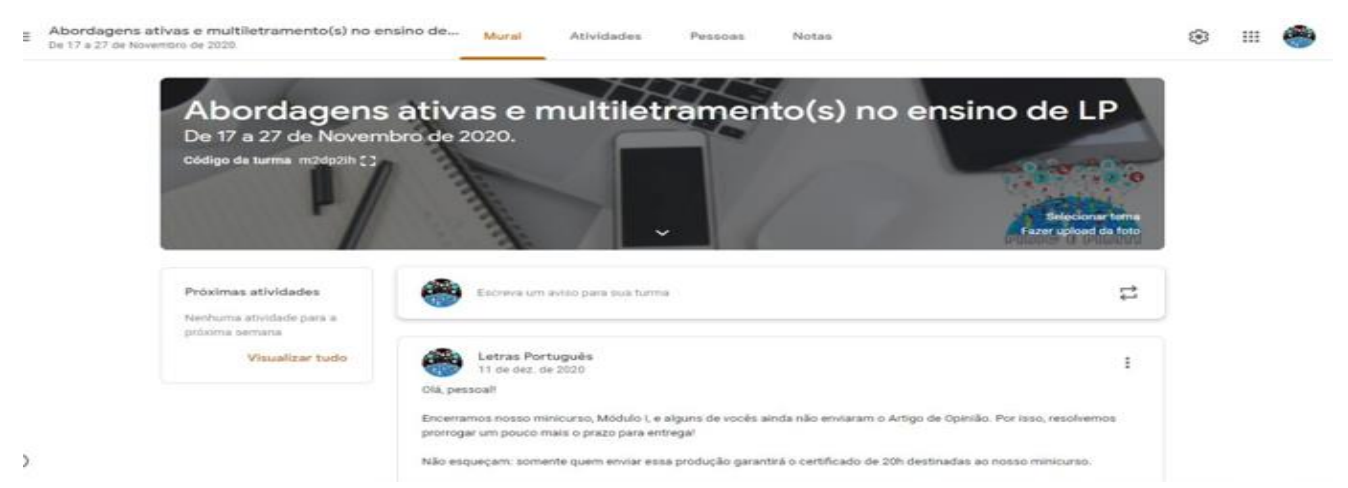

Fonte: Autores (2020).

Os resultados indicaram que o processo de participação atingiu êxito, considerando que dos 28 estudantes inscritos, houve registro de apenas 2 (duas) desistências. Dos 26 participantes, nove apresentaram participação considerada como incompleta pelos/as organizadores/as, por terem apresentado pouca ou nenhuma interação.

Para melhor visualização, apresentamos o Gráfico 1, que mostra que mais de 60\% dos/as participantes concluíram o curso. 


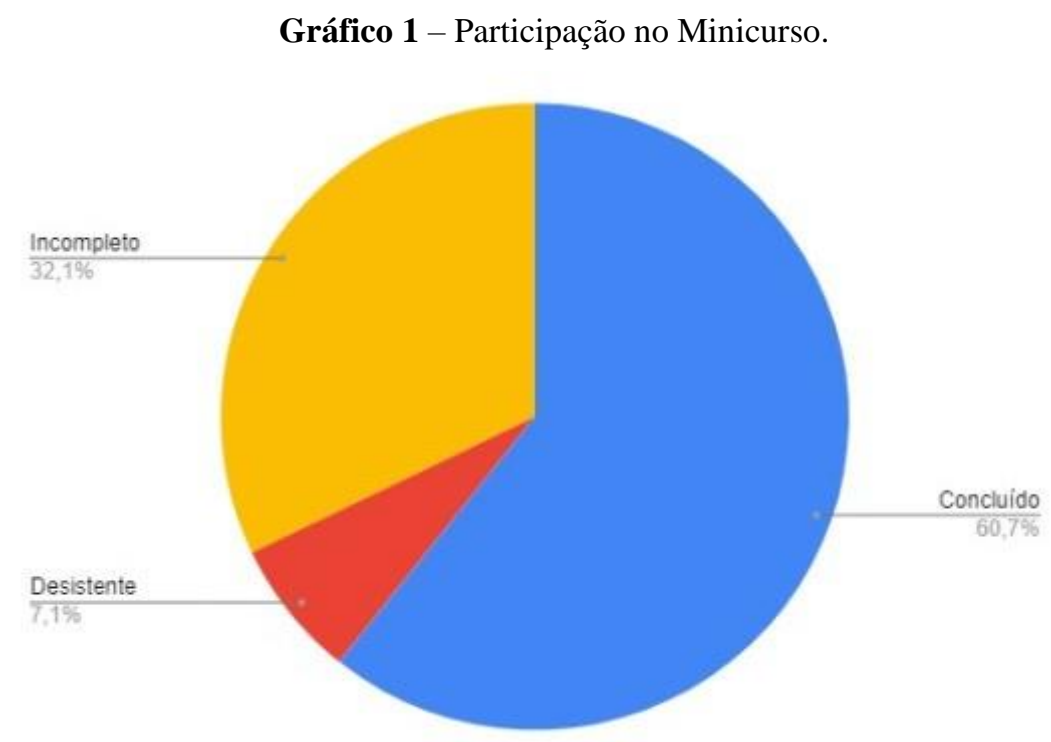

Fonte: Autores (2020).

\section{Dificuldades e desafios}

Desde a sua idealização, foi necessário que se fizesse uma análise detalhada acerca da qualidade do material e a forma de oferta do Minicurso. Questões técnicas, de recursos e financeiras foram consideradas. Ademais, temos vivenciado a inviabilidade quanto aos encontros presenciais, impossibilitados devido à Pandemia da Covid-19. No entanto, com a oferta de Auxílio Conectividade 2 pelo IFAL e com a possibilidade de oferta de cursos em plataformas on-line, verificou-se que todos os/as estudantes inscritos/as não indicaram dificuldades do ponto de vista de recursos ou financeiras. No entanto, por meio de questionário respondido pelos/as participantes/as, antes mesmo de se iniciar o Minicurso, foram identificados outros desafios a serem superados, conforme Gráfico 2, a seguir.

Gráfico 2 - Participação em cursos on-line.

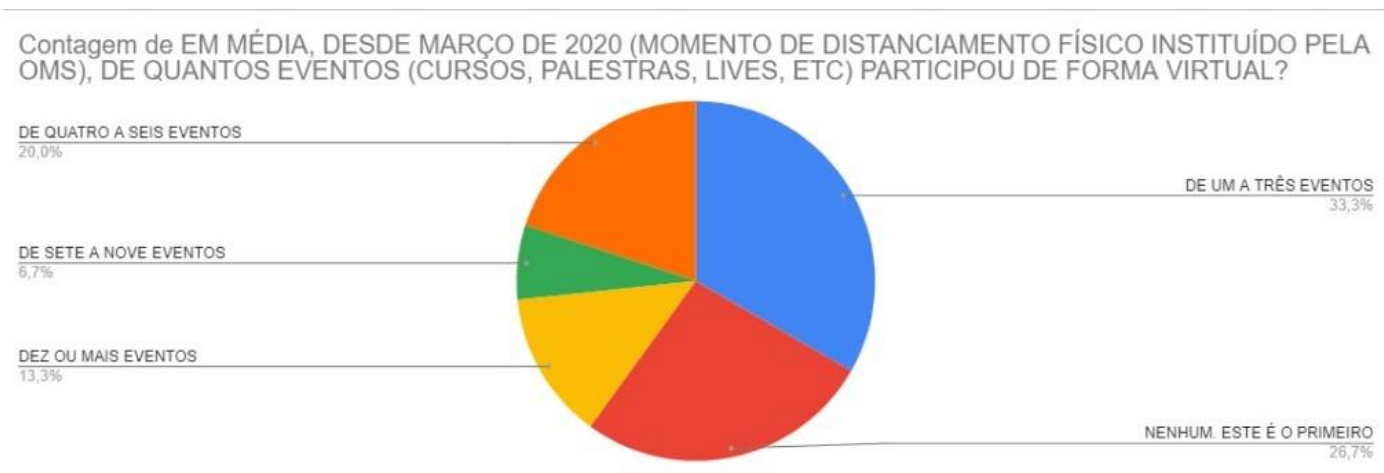

Fonte: Autores (2020).

Notamos que 26,7\% dos/as participantes responderam ser o Minicurso on-line "Abordagens Ativas e Multiletramento(s) no Ensino de LP" o primeiro do qual participaram desde o início do período de isolamento social físico. Enquanto 33,3\% responderam ter participado de no máximo 3 (três) cursos on-line, no mesmo período, previamente. Essa

\footnotetext{
${ }^{2}$ Portaria $\mathrm{n}^{\circ}$ 46, disponível em: https://www2.ifal.edu.br/o-ifal/assistencia-estudantil/arquivos/resolucao-no-46-2020-aprovar-ad-referendumas-normas-de-concessao-do-auxilio-conectividade-1.pdf
} 
situação estimulou os/as organizadores/as a buscarem tornar o curso o mais atrativo possível, com material de qualidade e vias múltiplas de comunicação com os/as participantes, por meio de feedbacks. No entanto, a superação da resistência às telas foi um desafio evidenciado por nós com base nas interações dispostas pelos/as participantes.

Gráfico 3 - Dificuldade para realização de leitura em tela.

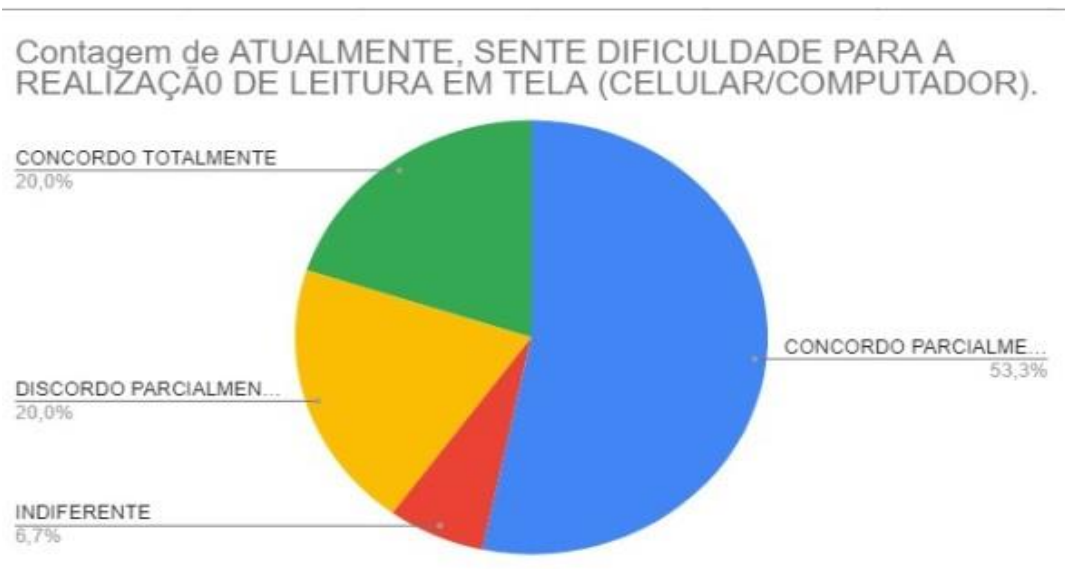

Fonte: Autores (2020).

No Gráfico 3 disposto anteriormente, nota-se que apenas 6,7\% dos/as entrevistados/as declararam não ter dificuldades quanto à leitura em telas, ou seja, afirmaram ser indiferente à plataforma de leitura. Mais de $90 \%$, portanto, declararam ter, ainda que parcialmente, problemas com eventos e material disponibilizado on-line. Para tornar o Minicurso diferenciado e superar as dificuldades, diversificamos os formatos dos materiais oferecidos. Além disso, os/as estudantes indicaram interesses nas interações, em tempo real, com uso de arquivos em áudio, imagens e textos, no aplicativo Whatsapp; já na apresentação do/as organizadores/as, fizemos uso de podcasts.

Os/as organizadores/as analisaram como pertinentes os podcasts por serem estes considerados aportes metodológicos ligados à multimodalidade. Atualmente, os smartphones são frequentemente usados para se obterem informações das mais variadas. Podcasts podem ser ouvidos on-line, mas também podem ser salvos ("baixados") para ser escutados livremente. A educação, pois, também se vale dessa tecnologia, tornando acessíveis assuntos em formato de aulas, cursos ou mesmo conversas em tons informais.

Cite-se ainda que, com os questionários respondidos pelos/as participantes, concluímos não haver participantes com necessidades especiais quanto à visão ou à audição. Ou seja, apresenta-se como desafio futuro viabilizar conteúdos inclusivos para grupos distintos que possam vir a acessar o Minicurso, de domínio público, inclusive aqueles/as que tenham algum tipo de deficiência.

A Figura 3 a seguir traz um esboço de como foi disposta no AVA a sequência de podcasts voltada aos/às cursistas, sendo 4 (quatro) no total. 
Research, Society and Development, v. 11, n. 2, e35511225697, 2022

(CC BY 4.0) | ISSN 2525-3409 | DOI: http://dx.doi.org/10.33448/rsd-v11i2.25697

Figura 3 - Podcasts gravados pelos organizadores e disponibilizados no AVA.

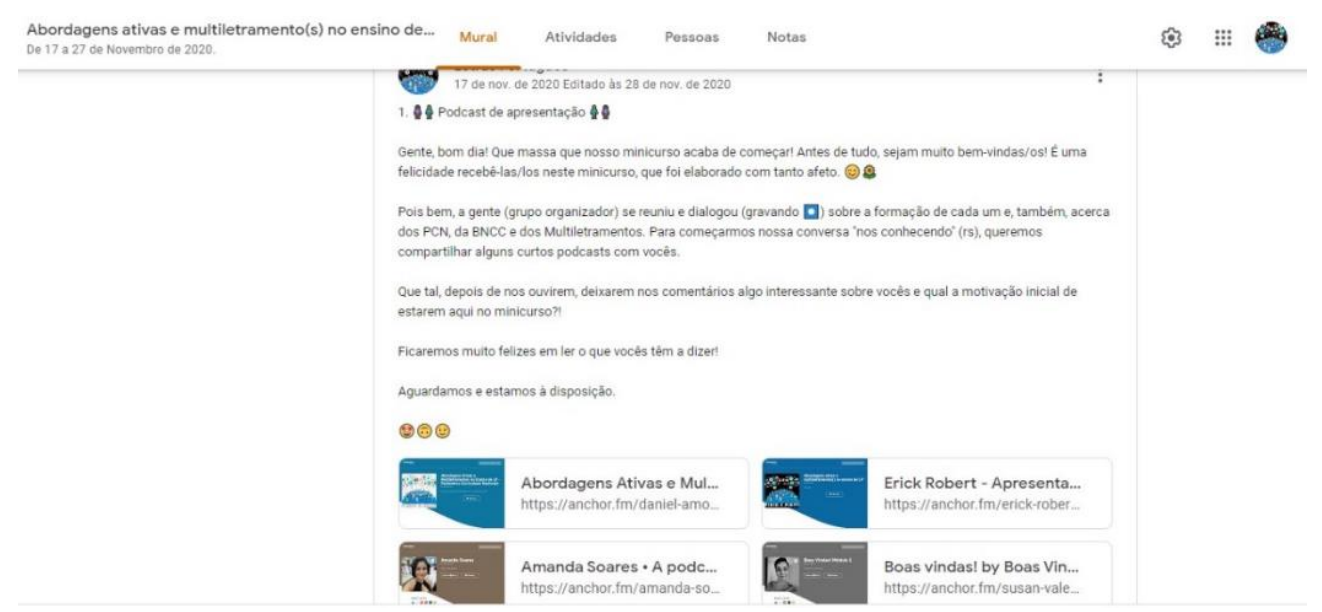

Fonte: Autores (2020).

Com base nisso, convém esclarecer que cada um dos podcasts é correspondente à elaboração de cada um dos/as bolsistas envolvidos/as nos projetos de pesquisa, que foram, para fins de oferta do minicurso em tela, ministrados de modo integrado, considerando-se PIBIC e PIBITI (Ifal), ambos coordenados pelo mesmo grupo de orientadores/as.

\section{Interações nos Fóruns Propostos no AVA}

A possibilidade de interação entre os/as participantes e destes com os/as organizadores/as foi propiciada desde a apresentação do minicurso, em sua página inicial. Buscou-se garantir que nenhum comentário ficasse sem resposta e que nenhuma dúvida ficasse sem ser sanada.

Preservando a identidade dos/as participantes, salienta-se que cada opinião ou comentário foi levado em conta, inclusive para coleta de dados e viabilização do corpus da pesquisa, como se pode verificar na Figura 4.

Figura 4 - Interações no $\mathrm{AVA}^{3}$

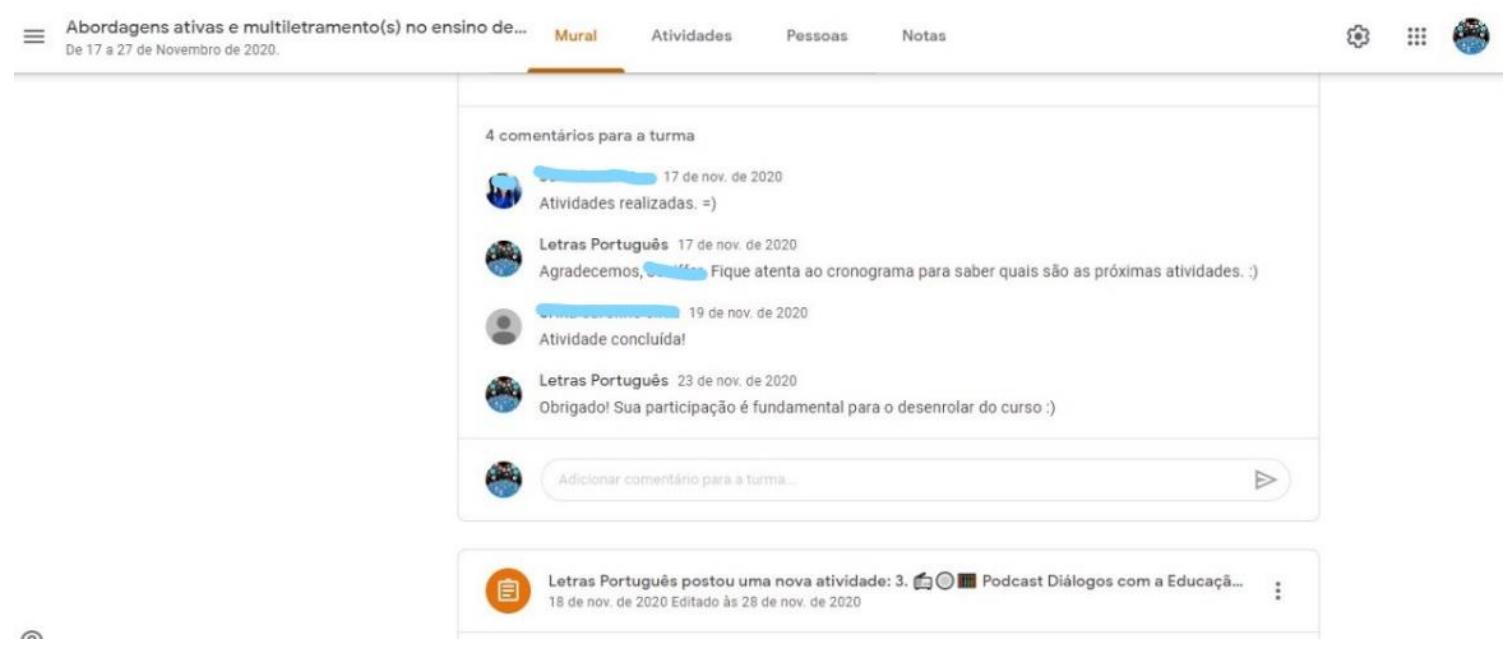

Fonte: Autores (2020).

\footnotetext{
3. Aliados a princípios éticos, foram preservadas as identidades dos colaboradores do estudo.
} 
Uma vez criado um tópico de discussão, os organizadores acompanhavam e analisavam os comentários dos participantes, sempre fornecendo feedback e esclarecendo dúvidas. A Figura 5, a seguir, demonstra algumas das interações dispostas no AVA, bem como um comentário realizado por um dos bolsistas quanto à análise das marcações de subjetividade, características de textos de predominância argumentativa.

Figura 5 - Participações no AVA (foram preservadas as identidades dos colaboradores).

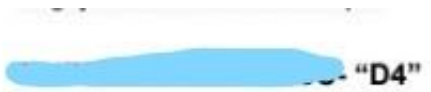

1 - Acredito ser um conjunto de possibilidades de dispositivos como rádio, televisão, telefone, smartphones, computadores, tablet, internet que permitem a troca e armazenamento de informaçōes, e mais, além de transmissăo e troca de informaçōes de maneira analógica ou digital, dando destaque ao papel da comunicaçăo neste processo.

2 - A utilização dos gêneros digitais em salas de aula na disciplina de Língua Portuguesa entendo que seja a forma onde se efetivam a importância do uso dos textos disponiveis na Internet, em conjunto com os gêneros textuais tradicionais, apresentando propostas de atividades envolvendo chat, blog, hipertexto, home Page, fórum de discussão e email, dentre outros.

\section{3- Por enquanto, nåo!}

Comentários do avaliador: Além de suas respostas comprovarem o engajamento em cada etapa do curso, a/o participante expressou-se em primeira pessoa, apresentando, pois, marcas de subjetividade, características de textos argumentativos.

Fonte: Autores (2020).

A Figura 5 contém respostas de um/a dos/as participantes do Minicurso, genericamente denominado(a) "D4" para que sua identidade seja preservada, como pré-requisitos apresentados pelos/as organizadores/as, respondidos no AVA. Note-se que as respostas foram detalhadamente analisadas e, assim, pôde-se chegar a conclusões acerca do engajamento do/a participante, bem como sobre a identificação de características de alguns gêneros textuais.

\section{Deslocamentos às Próximas Etapas da Pesquisa}

As etapas futuras da pesquisa visam à elaboração do produto educacional (e-book) a ser apresentado e depositado na plataforma EduCapes, com licenciamento gratuito do Criative Commons. Os Produtos Educacionais não somente conferem o resultado obtido em empreendimentos investigativos dessa natureza, mas também têm o propósito que outros/as pesquisadores/as, engajados em práticas investigativas diversificadas, possam se apropriar do percurso traçado no sentido de se filiar e, ainda, se contrapor às etapas percorridas e à base acessada, tanto teórico quanto metodologicamente.

\section{Considerações Finais}

Neste artigo, pudemos debater parcialmente, a partir de uma das etapas por nós traçada, haja vista a intenção de, em alguma medida, contribuir para a problematização de concepções e práticas de multiletramento(s) acadêmico-docente no contexto da formação inicial docente em nível universitário e, por conseguinte, uma formação docente mais críticoemancipatória e reflexiva, o que, certamente, reverberará nas futuras práticas pedagógicas desses sujeitos.

Confirma-se a necessidade de promoção de eventos on-line não só como extensão aos eventos físicos, mas como alternativa viável em períodos de impossibilidade de encontros presenciais, tendo em conta a dinâmica de aprendizagem 
proporcionada pelas tecnologias digitais em atividades remotas. A partir dos dados analisados, tem-se constatada certa dificuldade na conciliação de atividades acadêmico-científicas - ditas oficiais - com aquelas ofertadas em caráter optativo, como é o caso da pesquisa-ação descrita como minicurso ofertado, o que tem levado a uma baixa interação nos momentos destinados à oferta de ações nesse sentido. Isso se confirmou na oferta dos momentos síncronos, assíncronos e, também, semissíncronos.

Em filiação a princípios e a concepções de Raquel Fiad (2015), de Brian Street (2014) e de Oliveira (2017), nos quais apontam que o futuro para os estudos dos letramentos está na interdisciplinaridade, combinando as perspectivas dialógica e etnográfica na pesquisa e no ensino da escrita acadêmica, além de em teorias linguísticas e de base antropológica.

Mediante a experiência com o minicurso "Abordagens Ativas e Multiletramento(s) no Ensino de LP", percebeu-se que, para que a oferta de cursos nesse formato seja atrativa, deve haver divulgação eficaz, qualidade do material ofertado, interação entre os/as colaboradores/as e possibilidade de contato frequente com os/as organizadores/as para solução de dúvidas e questionamentos sobre o andamento do minicurso, além da oferta de certificação por meio do grupo de pesquisa a que nos filiamos, como foi o caso do GEPEPT (CNPq/Ifal).

Temos, com base na experiência do minicurso ofertado, refletido sobre os dados coletados e analisados a fim de subsidiar desdobramentos da investigação em outras propostas de minicurso, principalmente no que diz respeito ao uso das metodologias ativas tanto por professores/as em formação inicial, como foi o caso do estudo realizado, quanto na utilização de tais abordagens por docentes atuantes em salas de aula dos anos finais do ensino fundamental e do ensino médio, especialmente, no componente curricular Língua Portuguesa, tendo em vista a área de concentração de todos os envolvidos, na condição de pesquisadores/as, no presente estudo.

\section{Agradecimentos}

Agradecemos ao apoio prestado pelo Instituto Federal de Educação, Ciência e Tecnologia de Alagoas (Ifal), por meio da Pró-Reitoria de Pós-Graduação, Pesquisa e Inovação (PRPPI), que tem anualmente lançado editais de pesquisa e garantido, em tempos de escamoteamento de pesquisas no Brasil, principalmente, nas Humanidades, a produção do conhecimento científico mediante um trabalho sistematizado e articulado de pesquisadores/as (orientadores/as e pesquisadores/as iniciantes) que defendem o fazer científico e o compromisso social como amalgamados nos diálogos pulsantes dos debates de sala de aula, em específico, neste caso, no lócus do Curso de Licenciatura em Letras-Português do Campus Maceió/Ifal. A pesquisa, com doze meses de duração, de agosto de 2020 a julho de 2021, contou com o apoio financeiro a um dos bolsistas do Conselho Nacional de Pesquisas (CNPq), que, pela análise da proposta submetida ao Edital da PRPPI/Ifal à época, ficou empatada como primeiro lugar na seleção. Ademais, agradecemos ao Mestrado Profissional em Educação Profissional e Tecnológica, o ProfEPT/Ifal (lócus de atuação do/a orientador/a da pesquisa em tela, e de um dos estudantes pesquisadores), que tem se pautado em investigações-ações voltadas ao Ensino Médio Integrado na Rede Federal de Ensino com vistas ao desenvolvimento de Produtos/Processos Educacionais na melhoria de discussões que enaltecem a formação humana integral, cuja reflexividade é central nos diálogos que envolvem a profissionalização e o mundo do trabalho.

\section{Referências}

Brasil. (2018). Base Nacional Comum Curricular (BNCC). http://basenacionalcomum.mec.gov.br/ .

Branco, E. P. et al. (2019). BNCC: a quem interessa o ensino de competências e habilidades? Rev. Debates em educação. 12(27). https://www.seer.ufal.br/index.php/debateseducacao/article/view/7505\#: :text=O\%20presente\%20estudo\%20objetiva\%20identificar,ensino\%2C\%20em\%20c onson\%C3\%A2ncia\%20com\%20a.

Bunzen, C. Apresentação. (2014). In: STREET, Brian. Letramentos sociais: abordagens críticas do letramento no desenvolvimento, na etnografia e na educação, trad. Marcos Bagno. Parábola Editorial, p. 7-11. 
Cardoso, N. S., Cavalcanti, R. J. de S., \& Lima-Duarte, F. K. (2020). Implicações textual-discursivas na composição do gênero meme: uma análise se sua constituição. Programa de Pós-graduação em Educação (PPGE). Revista Debates em educação, Vol. 11, n. 25, maio/ago. Universidade Federal de Alagoas, UFAL: Maceió, 2020. https://www.seer.ufal.br/index.php/debateseducacao/article/view/8693..

Castro, M. H. G. (2020). Breve histórico do processo de elaboração da Base Nacional Comum Curricular no Brasil. Revista Em aberto, Brasília. 33(107), 95112. http://rbepold.inep.gov.br/index.php/emaberto/article/view/4530.

Cavalcanti, R.J.de S. (2019). A Argumentação no processo de formação docente: reflexões dos egressos do PIBID subprojeto Letras/Português da Universidade Federal de Alagoas - UFAL. Relatório Final de Pós-Doutorado. Programa de Pós-Graduação em Letras e Linguística. Universidade Federal de Alagoas, UFAL: Maceió.

Cavalcanti, R. J. S. et al. (2020). Memórias literárias de alunos licenciandos em Letras: problematização acerca do letramento literário. Revista Educação \& Linguagem (REdLi). p. 24-39. https://www.fvj.br/revista/revista-educacao-e-linguagem/edicoes/2020-1/

Cavalcanti, R.J.de S, \& Felix, Daniel Amorim de Oliveira. (2020). Multiletramentos à luz da BNCC: práticas pibidianas no subprojeto Letras do Instituto Federal de Alagoas (IFAL). In: Maria Edna Porangaba do Nascimento; Juliana Oliveira de Santana Morais (Org.). Práticas em sala de aula: diálogos necessários. Arapiraca/AL: EDUNEAL, 1, 55-72.

Coscarelli, C.V., \& Ribeiro, A.E. (2017). Letramento Digital: aspectos sociais e possibilidades pedagógicas. (3.ed.). Ceale/UFMG: Autêntica, 2017.

Davilal, D.; De Souza, R. J., AR, Ma. A. R. (2013). O Uso de Textos Polêmicos em Sala de Aula: formação e prática docente. Educação \& Realidade, Porto Alegre, 38(4), 1207-1220, out./dez.

Ferraz, C. P. (2019). A etnografia digital e os fundamentos da Antropologia para estudos em redes on-line. Aurora: revista de arte, mídia e política. São Paulo, 12(35), 46-69, jun.-set. https://revistas.pucsp.br/aurora/article/view/44648.

Fiad, R. S. (2015). Considerações sobre Letramentos Acadêmicos no contexto brasileiro. Pensares em Revista. São Gonçalo-RJ, (6), 23-34, jan. / jun.

Ibiapina, I. (2008). Pesquisa colaborativa: investigação, formação e produção de conhecimentos. Brasília: Líber.

Lüdke, M.; \& André, M. E.D.A. (1986). Pesquisa em educação: abordagens qualitativas. São Paulo: EPU.

Marcuschi, 1. a. (2001). da fala para a escrita: atividades de retextualização. 2. ed. são paulo: cortez.

Noveli, M. (2010). Do Off-Line para o Online: A Netnografia como Um Método de Pesquisa ou o que Pode Acontecer quando Tentamos Levar a Etnografia para a Internet? Revista Organizações em Contexto, 2010. p.107-133. https://www.researchgate.net/publication/273481753_Do_OffLine_para_o_Online_A_Netnografia_como_Um_Metodo_de_Pesquisa_ou_o_que_Pode_Acontecer_quando_Tentamos_Levar_a_Etnografia_para_a_Internet.

Oliveira, G. F. (2017). Os Estudos dos Letramentos Acadêmicos no Brasil: Influências, Origens e Perspectivas. Dissol. Pouso Alegre, (5), 89-101, jan./jun..

Pereira, A. A. S., \& Monteiro, J. C. da S. M. (2020). A Netnografia como método de estudo de comportamento em ambientes digitais. Anais do III Simpósio Internacional Interdisciplinar em Cultura e Sociedade.

https://www.academia.edu/42991787/A_netnografia_como_m\%C3\%A9todo_de_estudo_do_comportamento_em_ambientes_digitais.

Ramos, M. N. Pedagogia das competências. Dicionário da educação profissional em saúde, FIOCRUZ.

http://www.sites.epsjv.fiocruz.br/dicionario/verbetes/pedcom.html..

Ribeiro, A.E. (2016). Textos multimodais: leitura e produção. São Paulo: Parábola.

Ribeiro, A. E. (2020). Que futuros redesenhamos? Uma releitura do manifesto da Pedagogia dos Multiletramentos e seus ecos no Brasil para o século XXI. Diálogo das Letras, Pau dos Ferros, 9, -19, e02011.

Ribeiro, A. E (2020). Textos multimodais na sala de aula: exercícios. Revista Triângulo, 13(3).

http://seer.uftm.edu.br/revistaeletronica/index.php/revistatriangulo/article/view/5005.

Rojo R.H., \& Moura, E.(orgs.). (2012). Multiletramentos na escola. São Paulo: Parábola.

Rojo R.H. (2020). Multiletramentos e TDICs em tempos de pandemia - Profa. Dra. Roxane Rojo. Youtube. https://www.youtube.com/watch?v=qp63KQbJX$\mathrm{E} \& \mathrm{t}=3 \mathrm{~s}$.

Shepherd, T.G., \& Saliés, T.G. (orgs.). (2013). Linguística da internet. São Paulo: Contexto.

Silva, V. C. O., \& Vieira, F.M.S. (2019). Ensino de Língua Portuguesa: contexto e a prática de multiletramentos. Appris Editora.

Thiollent, M. (1988). Metodologia da pesquisa-ação. (4.ed.) São Paulo: Cortez. 